\title{
MOSS SPECIES BENEFITS FROM BREAKDOWN OF CYCLIC RODENT DYNAMICS IN BOREAL FORESTS
}

\author{
Knut Rydgren, ${ }^{1,6}$ Rune H. ØKland, ${ }^{2}$ F. Xavier Pico, ${ }^{3,4}$ and Hans de Kroon ${ }^{5}$ \\ ${ }^{1}$ Sogn og Fjordane University College, Faculty of Science, P.O. Box 133, Sogndal N-6851 Norway \\ ${ }^{2}$ Department of Botany, Natural History Museum, University of Oslo, P.O. Box 1172 Blindern, Oslo N-0562 Norway \\ ${ }^{3}$ Estación Biológica de Donana CSIC, Pabellón del Perú, Avenida María Luisa s/n, Sevilla 41013 Spain \\ ${ }^{4}$ Center for Ecological Research and Forestry Applications (CREAF), Autonomous University of Barcelona, \\ Bellaterra (Barcelona) 08193 Spain \\ ${ }^{5}$ Department of Ecology, Radboud University Nijmegen, Toernooiveld 1, Nijmegen 6525 ED The Netherlands
}

Abstract. Bryophytes have increased in abundance in northern regions, and climate changes have been proposed to account for this change. However, changes in the population dynamics of microtine rodents may also contribute to changes in bryophyte abundance. New evidence indicates a tendency for microtine rodent population oscillations to change from periodicity of 3-5 years to become irregular or acyclic. The impact on ecosystem functioning is potentially great. We study the impact of variation in microtine rodent population characteristics, such as cycle length and amplitude, on the population dynamics of the boreal, clonal moss Hylocomium splendens. We use experimental and observational demographic data to construct 127 scenarios representing all combinations of disturbance type (gap formation and/or clipping), period (cyclic with 4, 6, 12, or 24 years between rodent peaks; or acyclic with constant or stochastically varying annual disturbance severity) and disturbance severity (fraction of individuals affected by disturbance in each year relative to the maximum disturbance carried out in the field experiment; seven levels). Population data collected in the field during 13 years were used as a baseline scenario. By subjecting all scenarios to stochastic matrix modeling, we demonstrate considerable impact of microtine rodent on the population dynamics of $\mathrm{H}$. splendens, most notably when rodent populations fluctuate with short periods and high peak disturbance severities. Under the same average disturbance severity, H. splendens population growth rates are highest in acyclic scenarios and are progressively reduced with increasing peak disturbance severities (i.e., with increasing period). Stochastic elasticity analyses show that in less variable environments mature segment survival contributes more to the population growth rate, while in more variable environments the regeneration pathway (branching of older parts of the plant) plays a stronger role, inevitably leading to lower population fitness. Our results support the hypothesis that breakdown of cyclic rodent population dynamics accentuates increase in the abundance of $\mathrm{H}$. splendens and other large bryophytes in boreal forests in Norway, observed empirically in recent years and primarily ascribed to climatic change.

Key words: boreal clonal moss; bryophytes; climatic change; disturbance; elasticity; Hylocomium splendens; matrix population models; microtine rodent cycles; resistance to herbivory; stochastic growth rate.

\section{INTRODUCTION}

In the last two decades major vegetation changes have been observed in northern regions. Bryophytes, one of the most important plant groups in boreal and arctic regions (Nilsson and Wardle 2005), have increased in abundance, annual production, and population density (Økland 1997, Økland et al. 2004, Knorre et al. 2006). Climate changes, rendering more favorable conditions for bryophyte growth, have been proposed to account for changes in the performance of bryophytes (Økland 1997, Økland et al. 2004, Knorre et al. 2006). However, we propose an alternative hypothesis that may also

Manuscript received 28 September 2006; revised 18 January 2007; accepted 25 January 2007. Corresponding Editor: T. J. Valone.

${ }^{6}$ E-mail: knut.rydgren@hisf.no contribute to the observed changes in bryophytes, namely a change in the impact of microtine rodents on bryophytes via a change in rodent population dynamics (from cyclic to acyclic).

Bryophytes make up an important food item for many microtine species (Hansson 1969, Tast 1991, BondrupNielsen 1993), and microtine rodents impact bryophytes by herbivory and trampling. This disturbance may be so severe and occur so frequently that it plays an important role in structuring plant species composition in northern boreal and alpine ecosystems (Ericson 1977, Moen et al. 1993, Virtanen et al. 1997, Grellmann 2002). Typically, microtine rodent populations oscillate with a periodicity of three to five years in boreal and alpine ecosystems, but up to 35 years may lapse without population peaks (Steen et al. 1990, Hansson 1999). However, in the last decades distinctly reduced regularity of microtine rodent 


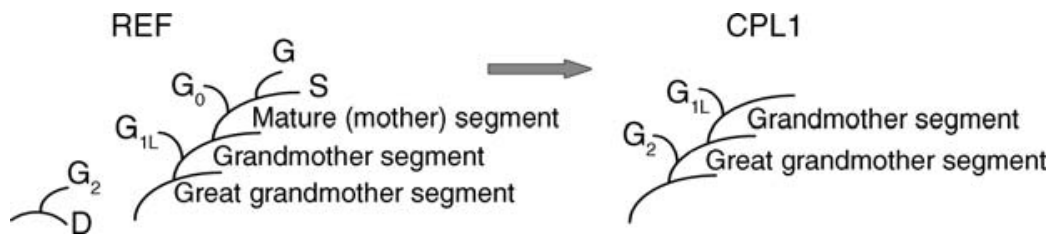

FIG. 1. Architecture of segment chains of the clonal moss Hylocomium splendens before manipulation (REF) and in the year following removal, by clipping, of all growing points (CLP1). Abbreviations are: S, mature (mother) segment; G, new growing point from the mature (mother) segment; $\mathrm{G}_{0}$, additional growing point (beyond the first) produced from a segment in its year of maturation; $\mathrm{G}_{1 \mathrm{~L}}$, growing point produced from dormant buds on the main axis (grandmother segment) after one year's delayed development; and $\mathrm{G}_{2}$, growing point produced with two or more years of delay or from detached fragments of indeterminable age in the diaspore bank (D).

population oscillations (approaching acyclic behavior) have been observed in many parts of Fennoscandia (Hanski and Henttonen 1996, Aars and Ims 2002). Little is known about how rodent oscillations influence plant populations, and in particular the effects of cyclic herbivory on long-term vegetation dynamics and the population dynamics of single species are basically unknown.

In the present study, we aim at investigating how changes in microtine rodent population oscillations, such as cycle length and amplitude, influence population dynamics of one of the most widespread and common moss species in the northern hemisphere, the clonal moss Hylocomium splendens (Persson and Viereck 1983). Microtine rodents influence $H$. splendens directly by grazing or by damaging apical meristems (growing points) and indirectly by trampling and making of runways which bring about removal of tissue and open the bryophyte carpet (Kalela and Koponen 1971, Ericson 1977). Thus, both loss of growing points and loss of whole segment chains are common, in particular in years when microtine rodents have high population peaks (R. H. Økland, unpublished data). Changes in the disturbance regime inflicted by rodents can thus be expected to have large consequences for $\mathrm{H}$. splendens dynamics.

We combine a 13-year unmanipulated reference data set with experimental data that mimic the two common types of rodent disturbance to construct 127 disturbance scenarios, represented by population matrices. Each scenario represents a combination of disturbance type (three types: grazing of growing points and/or creation of gaps in the bryophyte carpet), severity (seven levels), and period (six periods: cyclic with intervals of $4,6,12$, or 24 years between rodent peaks; and acyclic with constant or stochastically varying annual disturbance severity). Stochastic matrix models are used, by which all relevant combinations of disturbance type, period and severity are combined in a two-dimensional stochastic simulation model, and effects of each disturbance factor can be tested while the others are kept constant.

\section{Materials and Methods}

The species

Hylocomium splendens is a large, perennial, bisexual, clonal, pleurocarpous moss with modular growth $(\varnothing \mathrm{k}-$ land 1995). From the main axis of a one-year-old segment a single new growing point (G) normally emerges by sympodial ramification (branching) in spring, more rarely additional growing points $\left(\mathrm{G}_{0}\right)$ emerge as well (Fig. 1). Growing points become mature segments in their second autumn. Regeneration from older parts of intact segment chains also occurs occasionally, either with one year's delay (laterally $\left[\mathrm{G}_{1 \mathrm{~L}}\right]$ by development from intact segment chains or from segments on which the last year's growing point was grazed; or terminally $\left[\mathrm{G}_{1 \mathrm{~T}}\right]$ after termination [no growing point produced] the previous year), or with two or more years' delay or from detached fragments of indeterminable age $\left(\mathrm{G}_{2}\right)$ (Økland 1995, Rydgren et al. 2001). Germination of spores probably plays an unimportant role for maintaining populations in the absence of major ecological change (Økland 1995, Rydgren and Økland 2002, Cronberg et al. 2006).

Study area and collection of field data

Field data were collected in the Østmarka Nature Reserve, southeast Norway $\left(11802^{\circ}\right.$ E, $\left.59850^{\circ} \mathrm{N}\right)$, in Picea abies forests with understorey dominance by Vaccinium myrtillus (see Økland [1996] and Rydgren [1996] for a thorough description of the study area). The study area is situated outside the distribution range of the lemming (Lemmus lemmus), but other microtine rodents such as the wood lemming (Myopus schisticolor) and the grey-sided vole (Clethrionomus rufocanus) occur in Østmarka although not at high densities. Accordingly, the grazing impact on $\mathrm{H}$. splendens in the study area is low, normally $0-4 \%$ of the growing points are grazed annually (Økland 1997, Rydgren et al. 2001). The low natural background level of microtine rodent disturbance makes data from Østmarka suitable for modeling the effect of oscillating microtine densities because they provide a realistic description of the natural background disturbance level.

Background reference (REF) demographic data were obtained by following unmanipulated $\mathrm{H}$. splendens populations in plots $\left(0.0625 \mathrm{~m}^{2}\right.$ each $)$ for 13 successive autumns (1990-2002; see Økland 1995, 1997 for details of sampling). Experimental demographic data were obtained from 20 plots, $0.25 \mathrm{~m}^{2}$ each, two located randomly in each of 10 selected $100-\mathrm{m}^{2}$ blocks (see 


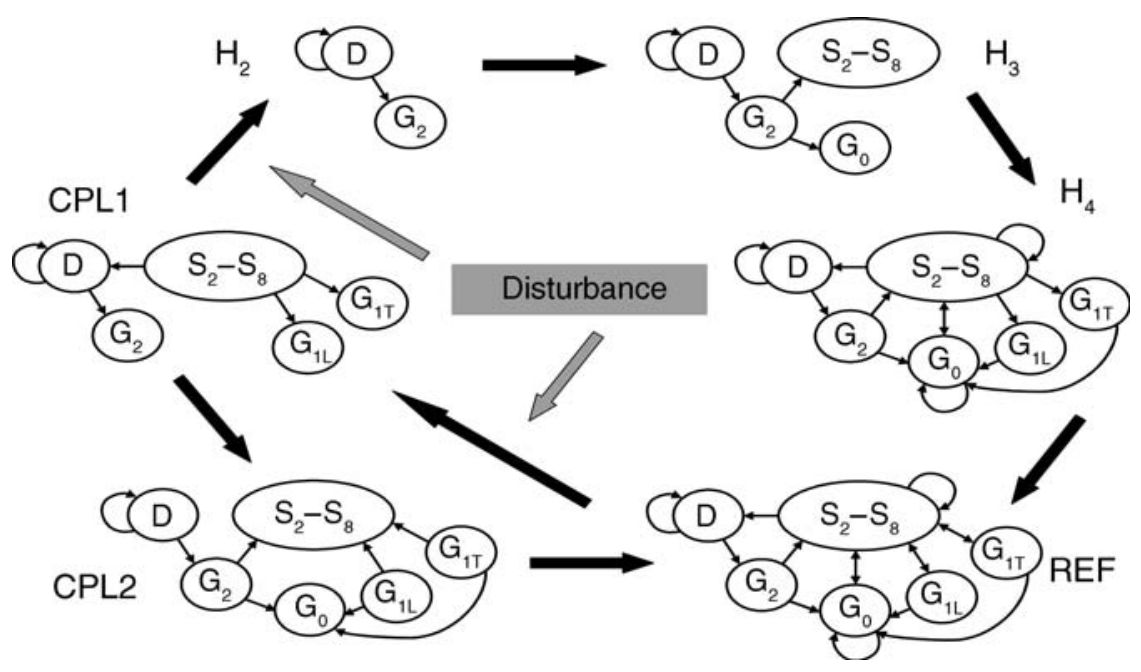

FIG. 2. Life cycle graphs of Hylocomium splendens: before manipulation (REF); in the year following removal, by clipping, of all growing points (CLP1); in the second year after clipping, without new clipping performed (CLP2); after clipping for two consecutive years $\left(\mathrm{H}_{2}\right)$; and in the two years following two consecutive years of clipping $\left(\mathrm{H}_{3}, \mathrm{H}_{4}\right)$, before the population is again fully recovered. See Fig. 1 and Materials and methods: Parameterization of transition matrices for further explanations.

Rydgren et al. 1998, 2001 for details of sampling). Treatments were applied only once, in September 1993, and annual censuses were performed in three successive autumns (1993-1995). Ten plots, one in each block, were subjected to clipped treatment (CLP) by cutting and removing all $\mathrm{H}$. splendens growing points $5 \mathrm{~mm}$ above their point of attachment (mimicking rodent grazing; Økland 1995). The other 10 plots were subjected to a gap formation (removal) treatment (REM) by which the cover of the bottom layer was reduced by approximately $50 \%$ by removing by tweezers all living bryophyte shoots from every second cell in a grid net with cell size $2.6 \mathrm{~cm}^{2}$ that was superimposed upon the bottom layer (Rydgren et al. 2001). In the following, all references to disturbance levels are given as percentage disturbance of the maximum level; for clipping this means a percentage of $100 \%$ (all segments were clipped) while for the gap formation (removal) this means a percentage of the $50 \%$ removal (half of the bottom layer was removed).

For each intact mature segment the number of growing points was recorded and size (DM, dry mass, expressed as base-2 logarithms whereby one unit corresponds to doubling of the size and sizes become normally distributed) was estimated from in situ morphological measurements of segment length, number of branches and length of the longest branch by a nonlinear regression model $\left(R^{2} 1 / 40.913, n\right.$ 1/4 328 mature segments; Økland 1995).

\section{The life cycle graph}

Mature H. splendens segments were classified into twelve life-stage classes (Fig. 2; also see Rydgren et al. 2001): seven S-classes for mature segments according to estimated dry mass $\left(\mathrm{S}_{2}\left[\log _{2} \mathrm{DM}, 3\right], \mathrm{S}_{3}\left[3<\log _{2} \mathrm{DM}\right.\right.$,
4], up to $\left.S_{8}\left[\log _{2} D M \quad 8\right]\right)$; four G-classes $\left(G_{0,}, G_{1 L}, G_{1 T}\right.$ and $G_{2}$ ) to account for growing points that have not yet developed into mature segments, arising by other branching processes than the normal, single ramification from the one-year-old main shoot axis; and a "diaspore bank" (D), included for technical reasons to account for the emergence of $\mathrm{G}_{2}$ growing points (Fig. 1). The halflife of D "individuals" was fixed to one year because a segment's regenerative ability is approximately halved each year after maturation (Økland 1995). In cases of multiple ramifications, the largest segment (upon maturity) was placed in the appropriate S-class, while the other(s) were recorded as $\mathrm{G}_{0}$. The number of mature segments one year before the start of the first transition period estimated according to Økland (1995) was used as the initial number of "individuals" in the diaspore bank.

\section{Parameterization of transition matrices}

We investigated how changes in rodent population oscillations influenced $H$. splendens population dynamics by combining reference and experimental field data into 12 different types of transition matrices of which five (unmanipulated REF matrices, two types of gap formation (or removal) REM matrices; and two types of clipping CLP matrices) were directly based on field data. Seven matrix types were derived from these five, including among others combinations of the two experimental treatments (Fig. 3; Appendix A). Seven disturbance levels $(2 \%, 4 \%, 8 \%, 16 \%, 32 \%, 64 \%, 96 \%)$ defined as the percentage of the population affected in each year relative to the maximum disturbance carried out in the field experiment (which was $50 \%$ removal for the REM1 matrix; and 100\% clipping in the CLP1) were applied. Temporal variation in the 12 unmanipulated 

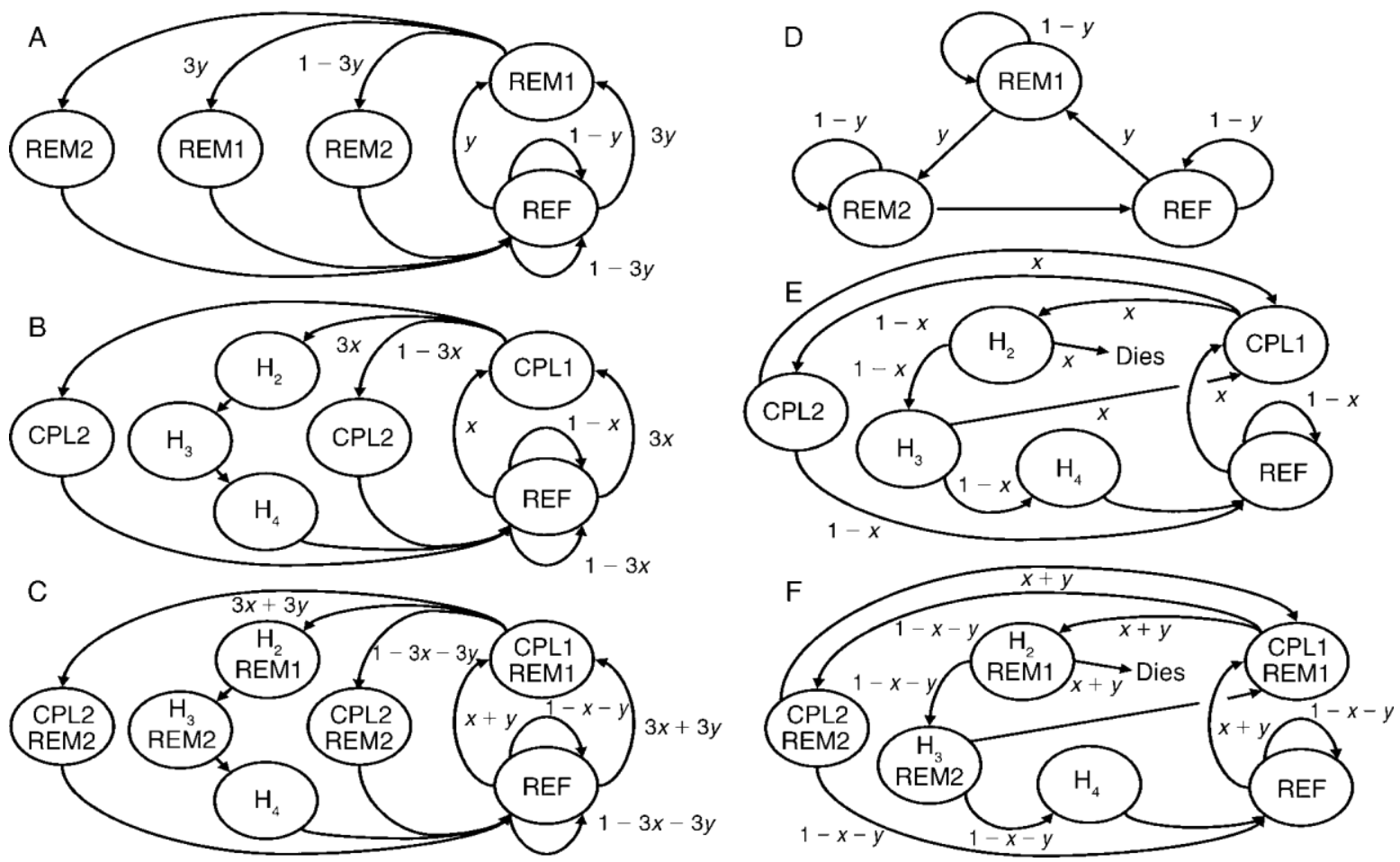

FIG. 3. Examples of stochastic disturbance treatment scenarios. Rows represent the three disturbance types: (A, D) gap formation; (B, E) clipping; and (C, F) combined. Columns exemplify two (out of six) disturbance period scenarios: (A-C) cyclic with fixed period of four years; and (D-F) acyclic with constant annual severity. Cyclic disturbance is modeled by two years of disturbance followed by two years without disturbance. In cyclic disturbance, the fraction of the population distributed in the first year was $\mathrm{y}, \mathrm{x}$, or $\mathrm{x} \mathrm{Py}$ (where $\mathrm{x}$ refers to removal and $\mathrm{y}$ to clipping). The population vector for disturbed ramets was multiplied by a disturbance matrix (REM1, CLP1, or CLP1/REM1), while the population vector for undisturbed ramets was multiplied by a reference matrix (REF). In the second year of disturbance, fractions 3y, 3x, or 3x p 3y of the part of the population that was (or was not) subjected to disturbance the previous year were subjected to disturbance (population vectors were multiplied by a disturbance matrix [REM1, CLP1 or $\mathrm{H}_{2}$, or CLP1/REM1 or $\left.\left.\mathrm{H}_{2} / \mathrm{REM} 1\right]\right)$. The remaining fraction $(1-3 y, 1-3 \mathrm{x}$, and $1-$ [3x $\mathrm{p} 3 \mathrm{y}]$ ) was left undisturbed and multiplied by a REF matrix or by REM2, CLP2, or CLP2/REM2, depending on ramet fate the previous year. Thereafter, two years without disturbance followed (or 4, 10, or 22 in periodic scenarios with 6-, 12-, and 24-year cycles, respectively).

(REF) matrices was used to "add" temporal variation to each matrix type, giving a total of 144 (12 3 12) matrices. These were used to model 127 disturbance scenarios (6 types of rodent population periodicity 33 types of disturbance 37 disturbance severities $p 1$ baseline scenario without disturbance).

The two gap formation, or removal, treatment types were REM1 for the first one-year period after applying the treatment (1993-1994) and REM2 for the second one-year period. Corresponding matrix types for experimentally clipped mosses were CLP1 for the first and CLP2 for the second one-year period after clipping. REM matrices retained the full structure of REF matrices and differed from each other and from REF matrices only in values for transition probabilities. CLP1 and CLP2 differed from each other and from REF matrices by a life cycle constrained by experimental manipulations to include some transitions, specific to each matrix, that were always zero (Fig. 2; Rydgren et al. 2001).
Single disturbance events are adequately modeled by REM1 followed by REM2 and CLP1 followed by CLP2 (Fig. 2; Rydgren et al. 2001). However, disturbance by microtine rodents, the populations of which build up and reach a peak over two consecutive years (Ericson 1977) does not only cause disturbance in one year but may bring about recurrent disturbances by which shoots disturbed in one year may be subjected to new disturbance the following year. In general, we handled recurrent disturbances by dividing a simulated population, i.e., the population vector, into subsets that entered disturbance-event specific loops which were represented by specific matrix sequences (Fig. 3) or that remained undisturbed (and were represented by REF matrices). Thus, a gap formation disturbance event in one year was represented by a REM1 matrix which was in the next year followed by another REM1 matrix for ramets that were disturbed also in the subsequent year and by a REM2 matrix for the other ramets (Fig. 3A). While a single clipping disturbance event (Fig. 3B) could be 
represented by a CLP1 matrix followed by a CLP2 matrix, recurrent clipping or clipping in combination with removal disturbance constrained the life cycle to such an extent that seven more types of matrices were needed. Three matrix types $\left(\mathrm{H}_{2}, \mathrm{H}_{3}\right.$, and $\mathrm{H}_{4}$; Fig. 2) were needed to account for consequences of clipping of growing points for two successive years. As relevant experimental field data were not available, the $\mathrm{H}$ matrices were constructed from CLP matrices (Appendix A). Fourth-year individuals arising by the clipping disturbance pathway were added to individuals arising by the REF pathway before the summarized population vector was used as input to the next round of the cycle (Figs. 2 and 3). This approach was also used for the longer cycles in order to obtain comparability between scenarios. Similarly, combined gap formation and clipping disturbances warranted creation of four new matrix types (CLP1/REM1, CLP2/REM2, H2/REM1, and $\mathrm{H}_{3} / \mathrm{REM} 2$; Fig. $3 \mathrm{C}$ and Appendix A). Building of the two acyclic disturbance scenarios was based upon the assumption that segments could be clipped three successive years before dying (Fig. 3E, F) due to exhaustion of resources as well as burial in the bryophyte carpet (Økland 2000). Thus, when segments in the $\mathrm{H}_{3}, \mathrm{H}_{4}$, and CLP2 matrices were clipped they entered the CLP1 matrix (Fig. 2).

Finally, temporal variation was "added" to CLP1, CLP2, REM1, and REM2 matrices separately but in comparable ways as detailed in Appendix B; the temporal variation added in the other seven disturbance matrix types follows from these four as explained in Appendix A. Thus 11 different disturbance matrix types each with 12 temporally variable matrices were constructed in such a way that each matrix in each series was to reflect "natural temporal variability" comparable to that of the corresponding REF matrix.

\section{Stochastic simulations}

We used a "factorial design" with three "factors" (disturbance properties) to create disturbance treatment scenarios: (1) disturbance type (three levels: gap formation, clipping disturbance, and combined; Fig. $3)$; (2) disturbance period (six levels: fixed time intervals (of $4,6,12$, and 24 years, respectively), acyclic constant disturbance (annually disturbed, severity constant), and acyclic stochastic disturbance (where the annual disturbance severity was drawn from a Poisson distribution with given mean comparable to the cycles, i.e., disturbance periods with fixed time interval); and (3) disturbance severity (seven levels: $2 \%, 4 \%, 8 \%, 16 \%$, $32 \%, 64 \%$, and $96 \%$, respectively). The total number of disturbance scenarios amounted to $336371 / 4126$. In addition a baseline scenario without disturbance was set up, based upon REF matrices only. Our "factorial design" corresponds to a two-dimensional stochastic simulation model to quantifying effects of variation in disturbance severity (for given combinations of disturbance type and period) on $\mathrm{H}$. splendens performance.
All cyclic disturbance scenarios included two consecutive years of disturbance, in which the disturbance severity the second year was set to be to three times higher than in the first year, in order to simulate the effect on the moss of consecutive stages of buildup and peak (cf. Ericson 1977), respectively, of microtine rodent populations, followed by the number of years without disturbance (REF matrices) needed to produce cycles of desired length. In cyclic disturbance scenarios severity refers to percentage of individuals subjected to disturbance in the year of maximal disturbance; in acyclic scenarios to the constant and the mean disturbance rates, respectively. To facilitate comparisons between cyclic and acyclic disturbance scenarios, average annual disturbance severities were for cyclic scenarios calculated as

$$
D_{\text {sev }} 1 / 4 \frac{D_{\max } p \partial 1=3 p D_{\max }}{n} 1 / 4 \frac{4 D_{\max }}{3 n}
$$

where $\mathrm{D}_{\max }$ is the disturbance severity the second year of disturbance, and $\mathrm{n}$ is the number of years in a population cycle.

Stochastic simulation of each scenario was made by drawing a sequence of matrices that represented the disturbance scenario in question. Each matrix was drawn at random and with equal probability among the 12 temporal replications of each matrix type. Each simulated population was followed for 4000 one-year intervals. The population vector for the REF population in 1990 was used as input to all simulations, after multiplication with a scaling factor that made the total number of individuals in $\mathrm{S}$ and $\mathrm{G}$ classes equal to 1000 . To estimate the stochastic growth rate (ln k), we used the following equation:

$$
\ln k_{s} 1 / 4 \frac{1}{3000}_{t^{1} / 41001} \ln \frac{N ð t p ~ 1 p}{N ð t^{p}}
$$

where $\mathrm{N}(\mathrm{t})$ refers to population size at time t. The initial 1000 time periods (years) were discarded to omit transient effects as recommended by Caswell (2001).

For the REM1 matrices we used the same transition matrices for this treatment as Rydgren et al. (2001) who studied the response of the remaining population after half of the population had been removed by disturbance, but as we were now interested in how loss of part of the population influenced the stochastic population growth rate, all population vectors were multiplied with 0.5 before multiplication (because of $50 \%$ removal) with the REM1 matrix in stochastic simulations, to take into account that half of the population is lost in this type of disturbance.

We estimated the elasticity of $\mathrm{k}_{\mathrm{s}}$ for the baseline simulation and for a selection of disturbance treatment scenarios by saving the path of matrices used for estimating $\ln \mathrm{k}_{\mathrm{s}}$ and then changing each element of each matrix in turn by a small amount (5\% reduction; see, e.g., Benton and Grant 1996) before a new $\ln \mathrm{k}_{\mathrm{s}}$ was 

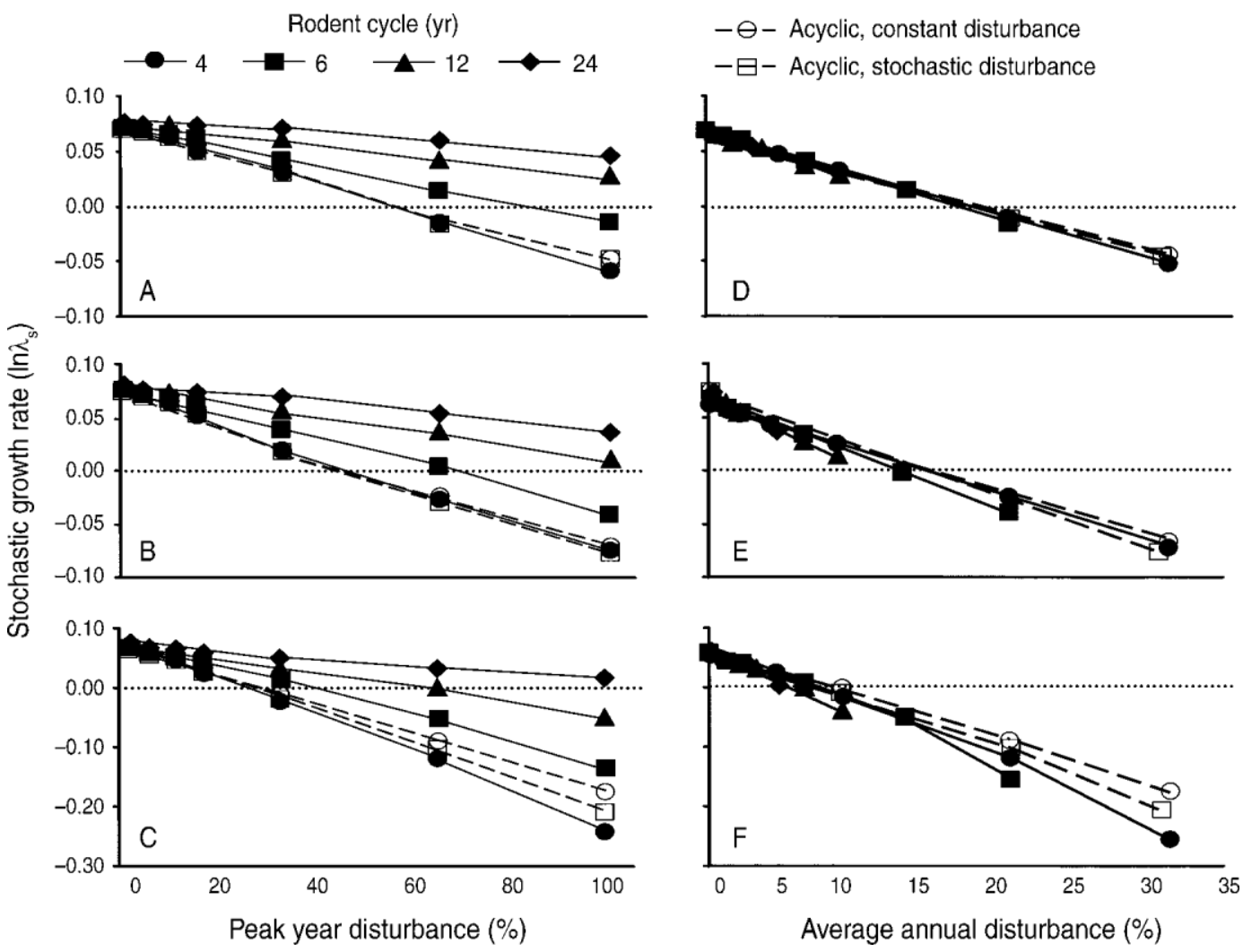

FIG. 4. Stochastic growth rates ( $\ln _{\mathrm{s}}$ ) of simulated Hylocomium splendens populations subjected to different disturbance treatment scenarios. Rows represent variation in disturbance severity and period of microtine rodent population cycles for each of the three disturbance types: (A, D) gap formation; (B, E) clipping; and (C, F) combined. Columns represent different scalings of disturbance severity, given as $(\mathrm{A}-\mathrm{C})$ percentage of disturbance during the peak year or as (D-F) the average annual percentage of disturbance. The percentages are calculated from the maximum empirical level, which is $100 \%$ for clipping and $50 \%$ for gap formation

recalculated. The percentage difference between the original $\ln \mathrm{k}_{\mathrm{s}}$ and the new $\ln \mathrm{k}_{\mathrm{s}}$ is the elasticity of that element (Aberg 1992, Caswell 2001).

All models were built and run (by macro-programming) in Lotus 1-2-3 version 5.01 (Lotus Development Corporation 1991).

\section{Results}

Population growth rates

The stochastic growth rate $\left(\operatorname{ln~}_{\mathrm{s}}\right)$ of the baseline simulation (reference $[\mathrm{REF}]$ matrices only) was 0.067 ; indicating a substantial long-term increase of $\mathrm{H}$. splendens populations in the study area in the period 1990-2002 in the virtual absence of microtine rodent disturbance. Addition of low-severity cyclic disturbance hardly changed $\ln \mathrm{k}_{\mathrm{s}}$, irrespective of disturbance type (Fig. 4). With increasing disturbance severity $\ln \mathrm{k}_{\mathrm{s}}$ decreased for all combinations of disturbance type and period (Fig. 4A-C) and the growth rate was affected less for scenarios with longer periods. For periods of 12 years or longer, decline below the population maintenance level ( $\ln \mathrm{k}_{\mathrm{s}}, 0.00$ ) was observed only for the combined disturbance scenario (gap formation and clipping; Fig. 4C). Comparison of scenarios with different disturbance periods but the same mean annual disturbance severity (Fig. 4D-F) revealed that the actual disturbance pattern influenced $\ln \mathrm{k}_{\mathrm{s}}$; for a given average disturbance severity the highest population growth rates were obtained for acyclic scenarios while $\ln \mathrm{k}_{\mathrm{s}}$ decreased with increasing period length (Fig. 4D-F), most prominently for the combined disturbance treatment (Fig. 4F).

\section{Elasticity analyses}

For the baseline simulation survival of mature segments made the most important contribution to $\mathrm{k}_{\mathrm{s}}$ (65\% of the total elasticity [Fig. 5A], of which $61 \%$ was contributed by transitions from large segments to large segments [i.e., between $\mathrm{S}_{6}, \mathrm{~S}_{7}$, and $\mathrm{S}_{8}$ ]). Further, $; 14 \%$ of the total elasticity was contributed by formation $\left(\mathrm{S}_{2-8}\right.$ to $\left.G_{0}\right)$ and maturation $\left(G_{0}\right.$ to $\left.S_{2-8}\right)$ of multiple growing points. Contributions from transitions to and from the diaspore bank (D), growing points produced with two or more years of delay or from detached fragments of indeterminable age in the diaspore bank $\left(\mathrm{G}_{2}\right)$ and growing points produced with one year's delay $\left(G_{1 L}\right.$ 


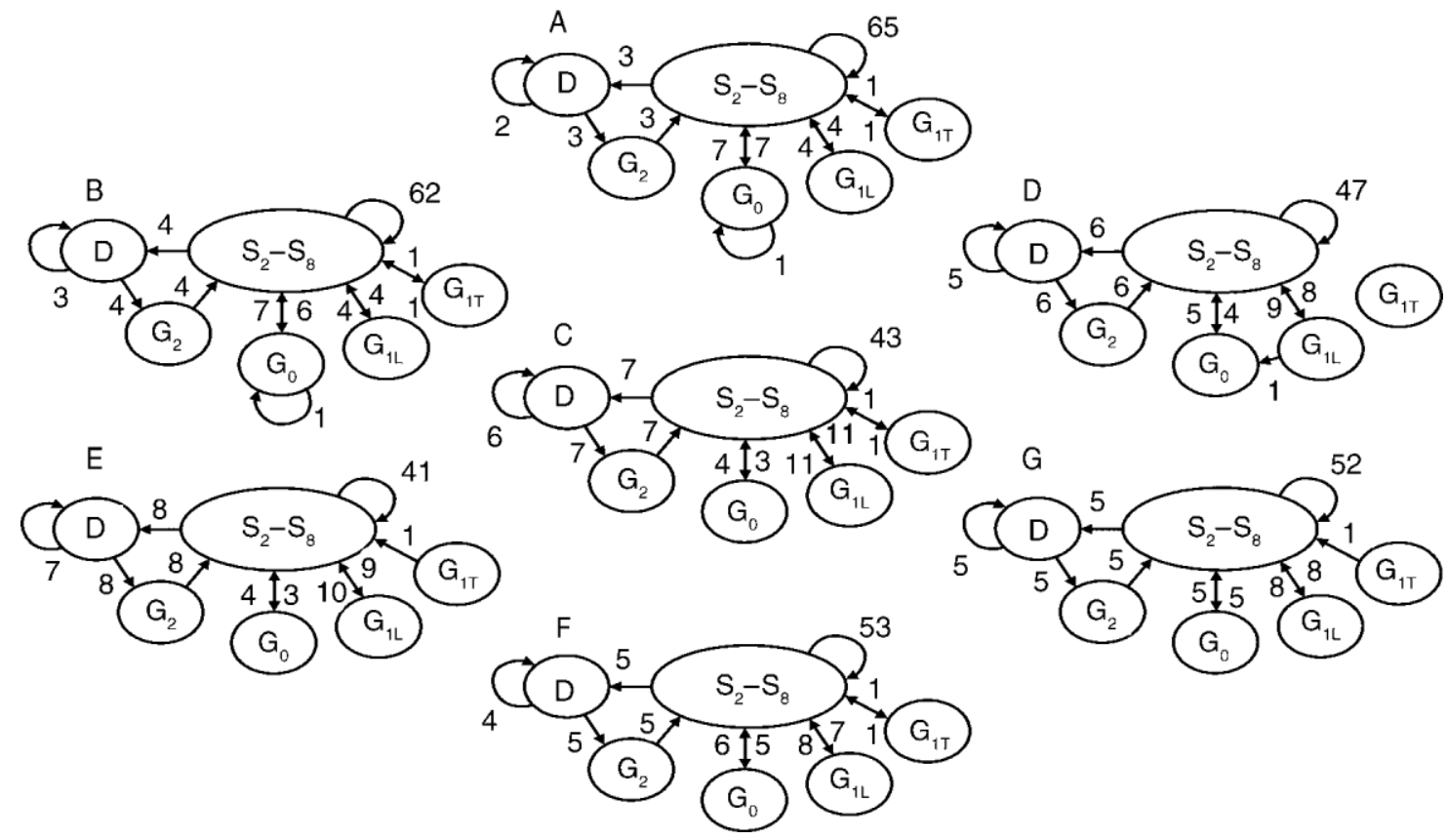

FIG. 5. Stochastic elasticities (only elasticities 1\% shown) for baseline simulation and scenarios with similar average annual disturbance, $D_{\text {sev }} 1 / 421.3$. (A) Baseline simulation with no disturbance. (B) Gap-formation scenario, 4-yr cycle, disturbance severity during the peak year $1 / 464 \%$. (C) Clipping, 4-yr cycle, disturbance severity during the peak year $1 / 464 \%$. (D) Combination of gap formation and clipping, 4-yr cycle, disturbance severity during the peak year $1 / 464 \%$. (E) Combination of gap formation and clipping, 6-yr cycle, disturbance severity during the peak year $1 / 496 \%$. (F) Combination of gap formation and clipping, acyclic constant disturbance. (G) Combination of gap formation and clipping, acyclic stochastic disturbance. Abbreviations are as in Fig. 1.

and $\mathrm{G}_{1 \mathrm{~T}}$ ) were all small $(<4 \%)$. Introducing disturbance at low severities only brought negligible changes in elasticity patterns compared to the baseline simulation, regardless of type of disturbance (results not shown). High disturbance severities (mean annual severities of approximately $D_{\text {sev }} 1 / 421 \%$ ) were necessary to bring about noticeable changes of elasticity patterns (Fig. 5). Among disturbance types, the gap formation treatment brought about the least change in elasticities compared to the baseline (Fig. 5B) while, for clipping as well as the combined treatment, substantial reductions of mature segment survival to $\mathrm{k}_{\mathrm{s}}$ were observed, to $41-53 \%$ of the total elasticity (Fig. 5). With clipping disturbance, regeneration of growing points with one years's delay $\left(G_{1 L}\right)$ and the pathway via the diaspore bank (D) to $G_{2}$ regeneration and their maturation into segments were substantially more important than in the baseline simulation (Fig. 5C). The contribution by transitions from large segments to large segments decreased (to a lower limit of $49 \%$ of the total contribution by mature segment survival) with increasing disturbance severity, indicating that the demographic importance of smaller segments increased with increasing disturbance severity.

Effects of disturbance type and period on elasticity patterns were evaluated using scenarios with mean annual severity of $\mathrm{D}_{\mathrm{sev}} 1 / 421.3 \%$ (Fig. 4F). For combined-disturbance scenarios, elasticity patterns for the four-year cyclic scenarios differed from those of acyclic scenarios in the lower contribution of mature segment survival to $k_{s}$, and the higher contribution of the pathway via the diaspore bank (D) to $\mathrm{G}_{2}$ regeneration into mature segments (Fig. 5D, F, G). Moreover, for four-year cyclic scenarios transitions from large segments to large segments contributed a lower percentage of the total elasticity of mature segment survival, $49 \%$ compared to $55 \%$ for both of the acyclic scenarios. The constant and stochastic acyclic scenarios had more or less similar elasticity patterns (Fig. 5F, G). With increasing period length (six-year cyclic scenarios, combined disturbances; Fig. 5E) these trends were strengthened: mature segment survival contributed $41 \%$ to $k_{s}$, and transitions from the large segments to large segments made up only $45 \%$ of the total elasticity of mature segment survival. Instead, the pathway from the diaspore bank via $G_{2}$ regeneration to mature segments and the $G_{1 L}$ pathway became relatively more important (Fig. 5C).

\section{Discussion}

We constructed stochastic disturbance treatment scenarios to explore how population dynamics of the clonal moss Hylocomium splendens are impacted by changes in disturbance regime resulting from changing microtine rodent population cycle characteristics (periodicity and amplitude). Understanding results of simulated disturbance starts with understanding the non- 
perturbed reference system for which a long-term annual population growth rate of $6.7 \%$ is obtained. This value confirms the strong increase of $\mathrm{H}$. splendens populations previously reported for the study area for the period 1990-2002 (cf. Økland 1997), which also fits into a pattern of increase for many bryophyte species on the boreal forest floor in the same period (Økland et al. 2004). The main reason for this increase is considered to be favorable climatic conditions for bryophyte growth (Økland 1997, Økland et al. 2004), but our results confirm our hypothesis that also change into longer and less regular periods of microtine rodent population cycles, with lower amplitudes (Hanski and Henttonen 1996, Aars and Ims 2002), will favor H. splendens population increase.

Our simulations show that the threshold disturbance severity at which $\mathrm{H}$. splendens populations remain sustainable (i.e., at which $\ln \mathrm{k}_{\mathrm{s}}-0.00$ ) increases with increasing period length. This is not unexpected since average annual disturbance severity decreases with period length but nevertheless accords with ecological theory and earlier studies, showing a positive effect of reduced herbivory for population growth of those few (vascular) plant species where effects over the entire life cycle have been studied (e.g., Doak 1992, Bastrenta et al. 1995, Ehrlen 1995, Rooney and Gross 2003, Knight 2004, Horvitz et al. 2005; but note that exceptions have also been reported [Escos et al. 1997]). Our simulations further suggest that relatively high rodent population impacts (short periods and high disturbance severities) are needed to bring about decline of $\mathrm{H}$. splendens populations: removal of $30 \%$ of $\mathrm{H}$. splendens growing points and loss of $15 \%$ of the segments in the peak year corresponds to $\ln \mathrm{k}_{\mathrm{s}} 1 / 40.00$. However, it is important to keep in mind that our simulations take a period with favorable growth conditions as their basis. Under less favorable background conditions lower disturbance severities will be needed to bring about population decline. Our simulations predict that in areas with large microtine rodent populations, periods of three to five years and much higher disturbance severities than 1530\% (Ericson 1977, Moen et al. 1993) are needed to reduce $H$. splendens populations to very low levels.

Although matrix modeling has been used to examine population effects of variation in a quantitative variable (e.g., Horvitz and Schemske 1986, Cipollini et al. 1994, Valverde and Silvertown 1997, Pascarella and Horvitz 1998), to our knowledge our study is the first to examine how changes in the pattern of variation, i.e., the cyclicity of disturbance severity, influences population development at similar average disturbance levels. Our results show that, under the same overall mean disturbance severity over the years, acyclic (e.g., constant) disturbance is more favorable to $\mathrm{H}$. splendens populations than cyclic disturbance. This is most clearly seen when rodent population cycles with different amplitudes but similar average disturbance severities are compared: the larger the peak disturbance severities, the lower the population growth rates (Fig. 4F). Differences in elasticity patterns between the acyclic and cyclic disturbance scenarios reveal the biological mechanisms behind the response of $\mathrm{H}$. splendens to disturbance variability: in more stable (acyclic) systems mature segment survival contributes relatively more to the population growth rate, while in less stable systems (systems with larger amplitude) the pathway from mature segment via the diaspore bank to regeneration of $\mathrm{G}_{2}$ growing points (that eventually become mature segments), and formation and regeneration of growing points on older parts of shoot chains, contribute relatively more to the total elasticity (the population growth rate). This is most clearly seen in the least stable system included in elasticity analyses, the six-year cyclic scenario (cf. Fig. 5). The main reason for the observed pattern is the slow buildup of segment size in $\mathrm{H}$. splendens shoot chains (Økland 1995). While in stable systems a population of relatively large segments can be upheld over decades, one severe disturbance event represents a considerable set-back because the regeneration pathway produces segments of smaller size, with lower branching frequencies, lower survival probabilities, and, hence, lower fitness (Økland 1995, 2000, Rydgren et al. 2001). Similar elasticity patterns are found in some vascular plants for which elasticities for the seed-to-seedling transition are higher in variable environments than in more stable environments (van Groenendael and Slim 1988). Furthermore, some modeling studies (e.g., of fire-dependent vascular plants [Hoffmann 1999, Menges and Quintana-Ascencio 2004, Liu et al. 2005]) report a tendency for poorer population development in response to change of the disturbance pattern from regular to less regular, and the sequence of environments, like crop rotations, is known to influence population growth rates (Mertens et al. 2002).

Our study demonstrates that $H$. splendens has a considerable resistance to a broad range and types of disturbances, in accordance with previous studies (Rydgren et al. 1998, 2001). Of the three main resistance mechanisms that are recognized for vascular plants, defense, escape, and tolerance (Boege and Marquis 2005), escape and tolerance are likely to be the most important ones in $\mathrm{H}$. splendens since microtine rodents eat this bryophyte extensively (Hansson 1969, BondrupNielsen 1993). H. splendens exhibits great variation in segment size (Økland 1995, 2000, Rydgren and Økland 2003), and the smaller segments are less vulnerable to disturbance by animals because in general they are situated at lower positions in the bryophyte carpet (Økland 2000). This view is supported by our elasticity analyses showing increasing relative contributions to the population growth rate of smaller relative to larger segments with increasing disturbance severity. Nevertheless, the most important resistance mechanism in $\mathrm{H}$. splendens is probably related to tolerance, i.e., traits that reduce the negative impact of herbivory on plant fitness like compensatory growth, increased photosynthesis, 
meristem activation and resource reallocation (Boege and Marquis 2005). Meristem activation seems to be a particularly important tolerance mechanism in $\mathrm{H}$. splendens, triggered by breaking of apical dominance after damage or removal of the apex (Rydgren et al. 2001). In our simulations, this is supported by the relatively higher contribution to $\mathrm{k}_{\mathrm{s}}$ of the total elasticity of branching from older shoot parts $\left(G_{1 L}\right.$ and $\left.G_{2}\right)$ with increasing disturbance severity, most prominent in the clipping treatment and in cyclic scenarios with a combination of gap formation and clipping disturbances (cf. Fig. 5). Even though such developmental plasticity is most prominent in plants with apical dominance (Rosenthal and Kotanen 1994) such as bryophytes, it also occurs in many vascular plants, for example in several Salix species that coexist with microtine rodents, taking advantage of relatively low herbivory severities following microtine peak years to quickly compensate for damage that occurred during the population peak (Elmqvist et al. 1987, Predavec and Danell 2001).

Growth of bryophyte populations in boreal and alpine environments may be enhanced by climatic changes into a moister and milder climate (Økland 1997, Økland et al. 2004), but as exemplified by our simulation study of one of the major species, $\mathrm{H}$. splendens, also by breakdown of cyclic rodent population dynamics. Both reduction in animal numbers and changes in patterns of population oscillations from cyclic with high amplitude to damped oscilliations or acyclic behavior may contribute to $H$. splendens population growth. However, more studies are needed to reveal if plant species generally perform poorer under more variable (or less predictable) disturbance regimes, provided that average disturbance severity is kept constant.

\section{ACKNOWLEDGMENTS}

We greatly appreciate discussion with Jan van Groenendael that inspired us to develop the ideas conveyed in this study, and the financial support from Sogn og Fjordane University College, the Local Research Fund, to K. Rydgren which made possible a research stay at Radboud University Nijmegen, the Netherlands. Thanks are due to the County Environmental Agencies in Oslo and Akershus for permission to undertake the study in Østmarka Nature Reserve, to Sigmund Hagvar for providing lodging at the Kjukebu field station, to the Norwegian Research Council, the TOV (terrestrial monitoring) program at the Directorate for Nature Management, and the Nansen Foundation and allied funds, for grants to field work for R. Økland, to Tonje Økland for placing the permanent monitoring plots at our disposal, and to Kjell Ivar Flatberg for advice on morphological measurements. We thank Nina Sletvold and two anonymous referees for valuable comments on the manuscript.

\section{Literature Cited}

Aars, J., and R. A. Ims. 2002. Intrinsic and climatic determinants of population demography: the winter dynamics of tundra voles. Ecology 83:3449-3456.

Aberg, P. 1992. A demographic study of two populations of the seaweed Ascophyllum nodosum. Ecology 73:1473-1487.

Bastrenta, B., J.-D. Lebreton, and J. D. Thompson. 1995. Predicting demographic change in response to herbivory: a model of the effects of grazing and annual variation on the population dynamics of Anthyllis vulneraria. Journal of Ecology 83:603-611.

Benton, T. G., and A. Grant. 1996. How to keep fit in the real world: elasticity analyses and selection pressures on life histories in a variable environment. American Naturalist 147: 115-139.

Boege, K., and R. J. Marquis. 2005. Facing herbivory as you grow up: the ontogeny of resistance in plants. Trends in Ecology and Evolution 20:441-448.

Bondrup-Nielsen, S. 1993. Food preference and diet of the wood lemming (Myopus schisticolor). Linnean Society Symposium Series 15:303-309.

Caswell, H. 2001. Matrix population models: construction, analysis, and interpretation. Second edition. Sinuauer, Sunderland, Massachusetts, USA.

Cipollini, M. L., D. A. Wallace-Senft, and D. F. Whigham. 1994. A model of patch dynamics, seed dispersal and sex ratio in the dioecious shrub Lindera benzoin (Lauraceae). Journal of Ecology 82:621-633.

Cronberg, N., K. Rydgren, and R. H. Økland. 2006. Clonal structure and genet-level sex ratios suggest different roles of vegetative and sexual reproduction in the clonal moss Hylocomium splendens. Ecography 29:95-103.

Doak, D. F. 1992. Lifetime impacts of herbivory for a perennial plant. Ecology 73:2086-2099.

Ehrlen, J. 1995. Demography of the perennial herb Lathyrus vernus. II. Herbivory and population dynamics. Journal of Ecology 83:297-308.

Elmqvist, T., L. Ericson, K. Danell, and A. Salomonson. 1987. Flowering, shoot production, and vole bark herbivory in a boreal willow. Ecology 68:1623-1629.

Ericson, L. 1977. The influence of voles and lemmings on the vegetation in a coniferous forest during a 4-year period in northern Sweden. Wahlenbergia 4:1-114.

Escos, J., C. L. Alados, and J. M. Emlen. 1997. The impact of grazing on plant fractal architecture and fitness of a Mediterranean shrub Anthyllis cytisoides L. Functional Ecology 11:66-78.

Grellmann, D. 2002. Plant responses to fertilization and exclusion of grazers on an arctic tundra heath. Oikos 98: 190-204.

Hanski, I., and H. Henttonen. 1996. Predation on competing rodent species: a simple explanation of complex patterns. Journal of Animal Ecology 65:220-232.

Hansson, L. 1969. Spring populations of small mammals in central Swedish Lapland in 1964-68. Oikos 20:431-450.

Hansson, L. 1999. Intraspecific variation in dynamics: small rodents between food and predation in changing landscapes. Oikos 86:159-169.

Hoffmann, W. A. 1999. Fire and population dynamics of woody plants in a neotropical savanna: matrix model projections. Ecology 80:1354-1369.

Horvitz, C. C., and D. W. Schemske. 1986. Seed dispersal and environmental heterogeneity in a neotropical herb: a model of population and patch dynamics. Pages 169-186 in A. Estrad and T. H. Fleming, editors. Frugivores and seed dispersal. Junk, Dordrecht, The Netherlands.

Horvitz, C. C., S. Tuljapurkar, and J. B. Pascarella. 2005. Plantanimal interactions in random environments: habitat- stage elasticity, seed predators, and hurricanes. Ecology 86: 3312-3322.

Kalela, O., and T. Koponen. 1971. Food consumption and movements of the Norwegian lemming in areas characterized by isolated fells. Annales Zoologici Fennici 8:80-84.

Knight, T. M. 2004. The effects of herbivory and pollen limitation on a declining population of Trillium grandiflorum. Ecological Applications 14:915-928.

Knorre, A. A., A. V. Kirdyanov, and E. A. Vaganov. 2006. Climatically induced interannual variability in aboveground 
production in forest-tundra and northern taiga of central Siberia. Oecologia 147:86-95.

Liu, H., E. S. Menges, and P. F. Quintana-Ascencio. 2005. Population viability analyses of Chamaecrista keyensis: effects of fire season and frequency. Ecological Applications 15:210-221.

Lotus Development Corporation. 1991. Lotus 1-2-3 version 5.01. Lotus Development Corporation, Cambridge, Massachusetts, USA.

Menges, E. S., and P. F. Quintana-Ascencio. 2004. Population viability with fire in Eryngium cuneifolium: deciphering a decade of demographic data. Ecological Monographs 74:7999.

Mertens, S. K., F. van den Bosch, and J. A. P. Heesterbeek. 2002. Weed populations and crop rotations: exploring dynamics of a structured periodic system. Ecological Applications 12:1125-1141.

Moen, J., H. Gardfjell, L. Oksanen, L. Ericson, and P. Ekerholm. 1993. Grazing by food-limited microtine rodents on a productive experimental plant community: does the "green desert" exist? Oikos 68:401-413.

Nilsson, M. C., and D. A. Wardle. 2005. Understory vegetation as a forest ecosystem driver: evidence from the northern Swedish boreal forest. Frontiers in Ecology and the Environment 3:421-428.

Økland, R. H. 1995. Population biology of the clonal moss Hylocomium splendens in Norwegian boreal spruce forests. I. Demography. Journal of Ecology 83:697-712.

Økland, R. H. 1997. Population biology of the clonal moss Hylocomium splendens in Norwegian boreal spruce forests. III. Six-year demographic variation in two areas. Lindbergia 22:49-68.

Økland, R. H. 2000. Population biology of the clonal moss Hylocomium splendens in Norwegian boreal spruce forests. 5 . Consequences of the vertical position of individual shoot segments. Oikos 88:449-469.

Økland, T. 1996. Vegetation-environment relationships of boreal spruce forest in ten monitoring reference areas in Norway. Sommerfeltia 22:1-349.

Økland, T., V. Bakkestuen, R. H. Økland, and O. Eilertsen. 2004. Changes in forest understory vegetation in Norway related to long-term soil acidification and climatic change. Journal of Vegetation Science 15:437-448.

Pascarella, J. B., and C. C. Horvitz. 1998. Hurricane disturbance and the population dynamics of a tropical understory shrub: megamatrix elasticity analysis. Ecology 79:547-563.
Persson, H., and L. A. Viereck. 1983. Collections and discussions of some bryophytes from Alaska. Lindbergia 9: $5-20$.

Predavec, M., and K. Danell. 2001. The role of lemming herbivory in the sex ratio and shoot demography of willow population. Oikos 92:459-466.

Rooney, T. P., and K. Gross. 2003. A demographic study of deer browsing impacts in Trillium grandiflorum. Plant Ecology 168:267-277.

Rosenthal, J. P., and P. M. Kotanen. 1994. Terrestrial plant tolerance to herbivory. Trends in Ecology and Evolution 9: $145-148$.

Rydgren, K. 1996. Vegetation-environment relationships of old-growth spruce forest vegetation in Østmarka Nature Reserve, SE Norway, and comparison of three ordination methods. Nordic Journal of Botany 16:421-439.

Rydgren, K., H. de Kroon, R. H. Økland, and J. van Groenendael. 2001. Effects of fine-scale disturbances on the demography and population dynamics of the clonal moss Hylocomium splendens. Journal of Ecology 89:395-405.

Rydgren, K., and R. H. Økland. 2002. Ultimate costs of sporophyte production in the clonal moss Hylocomium splendens. Ecology 83:1573-1579.

Rydgren, K., and R. H. Økland. 2003. Short-term costs of sexual reproduction in the clonal moss Hylocomium splendens. Bryologist 106:212-220.

Rydgren, K., R. H. Økland, and T. Økland. 1998. Population biology of the clonal moss Hylocomium splendens in Norwegian boreal spruce forests. IV. Effects of experimental fine-scale disturbance. Oikos 82:5-19.

Steen, H., N. G. Yoccoz, and R. A. Ims. 1990. Predators and small rodent cycles: an analysis of a 79-year time series of small rodent population fluctuations. Oikos 59:115-120.

Tast, J. 1991. Will the Norwegian lemming become endangered if climate becomes warmer? Arctic and Alpine Research 23: 53-60.

Valverde, T., and J. Silvertown. 1997. An integrated model of demography, patch dynamics and seed dispersal in a woodland herb, Primula vulgaris. Oikos 80:67-77.

van Groenendael, J. M., and P. Slim. 1988. The contrasting dynamics of two populations of Plantago lanceolata classified by age and size. Journal of Ecology 76:585-599.

Virtanen, R., H. Henttonen, and K. Laine. 1997. Lemming grazing and structure of a snowbed plant community - a long term experiment at Kilpisjarvi, Finnish Lapland. Oikos 79: $155-166$.

\section{APPENDIX A}

A table showing the different matrices used in the calculation of the different scenarios and how they were parameterized (Ecological Archives E088-140-A1).

\section{APPENDIX B}

A description on how matrix elements were modified to allow for variation among years in the 11 different types of disturbance matrices (Ecological Archives E088-140-A2). 